\title{
Damage on the Surface of Zinc Oxide Thin Films Etched in Cl-based Gas Chemistry
}

\author{
Jong-Chang Woo, Tae-Kyung Ha, Chen Li, Seung-Han Kim, and Jung-Soo Park \\ School of Electrical and Electronics Engineering, Chung-Ang University, Seoul 156-756, Korea
}

Kyung-Mu Heo

Department of Renewable Energy, Chung-Ang University, Seoul 156-756, Korea

Chang-II Kim ${ }^{+}$

School of Electrical and Electronics Engineering and Department of Renewable Energy, Chung-Ang University, Seoul 156-756, Korea

Received December 4, 2010; Revised March 8, 2011; Accepted March 12, 2011

\begin{abstract}
We investigated the etching characteristics of zinc oxide $(\mathrm{ZnO})$ thin films deposited by the atomic layer deposition method. The gases of the inductively coupled plasma chemistry consisted of $\mathrm{Cl}_{2}, \mathrm{Ar}_{\text {, and }} \mathrm{O}_{2}$. The maximum etch rate was $40.3 \mathrm{~nm} / \mathrm{min}$ at a gas flow ratio of $\mathrm{Cl}_{2} / \mathrm{Ar}=15: 5 \mathrm{sccm}$, radio-frequency power of $600 \mathrm{~W}$, bias power of $200 \mathrm{~W}$, and process pressure of $2 \mathrm{~Pa}$. We also investigated the plasma induced damage in the etched $\mathrm{ZnO}$ thin films using X-ray diffraction (XRD), atomic force microscopy and photoluminescence (PL). A highly oriented (100) peak was present in the XRD spectroscopy of the $\mathrm{ZnO}$ samples. The full width at half maximum value of the $\mathrm{ZnO}$ sample etched using the $\mathrm{O}_{2} / \mathrm{Cl}_{2} / \mathrm{Ar}$ chemistry was higher than that of the as-deposited sample. The roughness of the $\mathrm{ZnO}$ thin films increased from 1.91 $\mathrm{nm}$ to $2.45 \mathrm{~nm}$ after etching in the $\mathrm{O}_{2} / \mathrm{Cl}_{2} / \mathrm{Ar}$ plasma chemistry. Also, we obtained a strong band edge emission at 380 $\mathrm{nm}$. The intensities of the peaks in the PL spectra from the samples etched in all of the chemistries were increased. However, there was no deep level emission.
\end{abstract}

Keywords: Etch, Inductively coupled plasma, Zinc oxide, $\mathrm{Cl}_{2}, \mathrm{O}_{2}$

\section{INTRODUCTION}

In recent research, zinc oxide $(\mathrm{ZnO})$ was shown to be suitable for optoelectronic devices such as liquid crystal displays, solar cells, sensors and piezoelectric devices. $\mathrm{ZnO}$ thin films have unique properties, such as a direct band gap energy of $3.3 \mathrm{eV}$, exciton binding energy of $60 \mathrm{meV}$ and light transmission exceeding $80 \%$ [1-4]. Following the downsizing of the device scale, the conventional wet etching process is no longer suitable, due to the narrow line width of the devices and elaborate processing because of their isotropic properties. Problems are encountered in the wet etching process with devices of smaller size, such

\footnotetext{
${ }^{\dagger}$ Author to whom all correspondence should be addressed: E-mail: cikim@cau.ac.kr
}

as the over etching phenomenon. For this reason, anisotropic plasma etching is generally used in the fabrication process. The plasma induced damage causes critical errors in the operation of optoelectronic devices. Research into the use of $\mathrm{ZnO}$ has rapidly accelerated over the last few decades, such as its etching mechanism, thin film deposition, defect and doping control and $\mathrm{ZnO}$ based devices. However, insufficient studies have been done on the damage incurred by $\mathrm{ZnO}$ thin films during plasma etching in the dry etching process.

In this study, we investigated the surface and crystal structure damage of $\mathrm{ZnO}$ thin films and measured the etch rate using an inductively coupled plasma (ICP) system. The etch rate of the $\mathrm{ZnO}$ thin films was investigated as a function of the gas mixing ratio. The crystal damage on the etched surface of the $\mathrm{ZnO}$ thin 


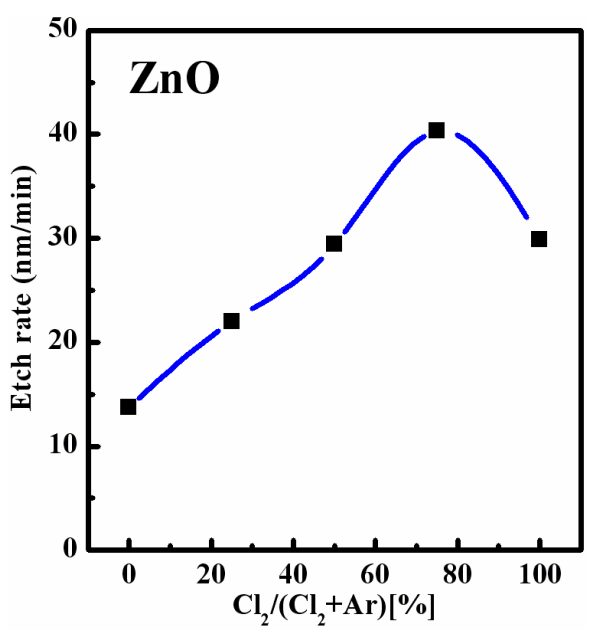

Fig. 1. Etch rate of zinc oxide $(\mathrm{ZnO})$ as a function of the $\mathrm{Cl} 2 / \mathrm{Ar}$ plasma mixture. The radio-frequency power was $600 \mathrm{~W}$, the bias power was $200 \mathrm{~W}$, and the process pressure was $2 \mathrm{~Pa}$.

films was investigated by X-ray diffraction (XRD). The etched surface reaction of the $\mathrm{ZnO}$ thin films were obtained to roughness by atomic force microscopy (AFM). We also determined the optical properties of the $\mathrm{ZnO}$ thin films by photoluminescence (PL) measurements.

\section{EXPERIMENTS}

In this work, ZnO thin film samples with a thickness of 200 $n m$ were grown on quartz substrates by atomic layer deposition (ALD). The etching experiments of the $\mathrm{ZnO}$ thin films were performed using an ICP system. The ICP system consisted of a chamber, electrodes, gas supply, mass flow controller (MFC) and turbo molecular pump. We investigated the etch rate of the $\mathrm{ZnO}$ thin films using a $\mathrm{Cl}_{2}$ based chemistry plasma that was mixed with $\mathrm{Ar}$ and $\mathrm{O}_{2}$ gases. The gas mixing ratio was controlled by the MFC. The conditions of the etching experiment were a total flow rate of $20 \mathrm{sccm}$, an radio-frequency (RF) power of $600 \mathrm{~W}$, a bias power of $200 \mathrm{~W}$, and a process pressure of $2 \mathrm{~Pa}$. The physical effects on the etched ZnO crystal were determined by XRD (D8Advance; Bruker AXS Co., Karlsruhe, Germany) with $\mathrm{Cu} \mathrm{K} \alpha \mathrm{l}$ radiation. The X-ray diffractograms were scanned over the angular range of $30-65^{\circ}(2 \theta)$ with a step length of $0.02^{\circ}(2 \theta)$. The surface morphology of the etched $\mathrm{ZnO}$ thin films was determined by AFM (NANO Station II, Surface Imaging Systems) in non-contact mode. All of the $\mathrm{ZnO}$ thin film bare samples were prepared with a sample size of $1 \mathrm{~cm} \times 1 \mathrm{~cm}$. The PL measurements were performed at room temperature and the exciting source was a HeCd laser (325 nm).

\section{RESULTS AND DISCUSSION}

The etching experiments of the $\mathrm{ZnO}$ thin films were performed in a chlorine based plasma. The objective of this experiment was to investigate the damage and modification on the $\mathrm{ZnO}$ thin film crystal structure and thin film surface.

Figure 1 represents the etch rate of $\mathrm{ZnO}$ as a function of the $\mathrm{Ar}$ gas content in the $\mathrm{Cl}_{2}$ plasma. The maximum etch rate of the $\mathrm{ZnO}$ thin film in the $\mathrm{Cl}_{2} / \mathrm{Ar}$ plasma was $40.3 \mathrm{~nm} / \mathrm{min}$ at an $\mathrm{RF}$ power of $600 \mathrm{~W}$, bias power of $200 \mathrm{~W}$, and process pressure of $2 \mathrm{~Pa}$. In our previous research and that performed by others, the chemical reactions on the $\mathrm{ZnO}$ thin film in the $\mathrm{Cl}_{2}$ plasma led to the formation of the compound, $\mathrm{Zn}_{\mathrm{x}} \mathrm{Cl}_{\mathrm{y}}$, from $\mathrm{Cl}$ radicals [5-8]. The

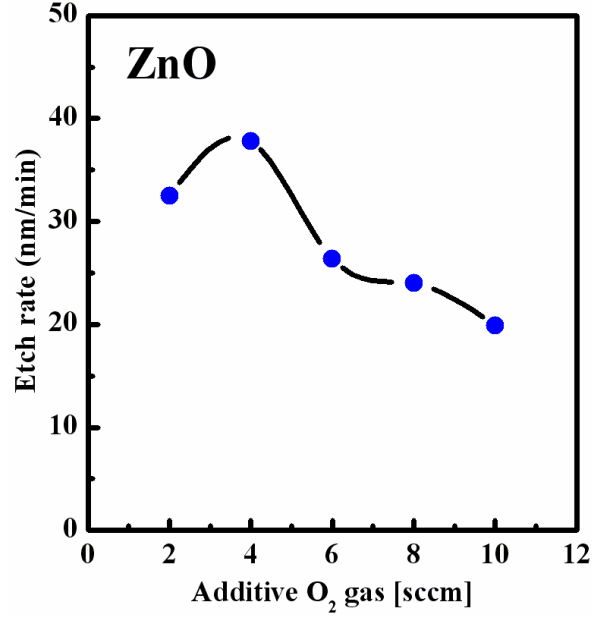

Fig. 2. Etch rate of zinc oxide $(\mathrm{ZnO})$ as a function of $\mathrm{O} 2$ content in the $\mathrm{Cl} 2 / \mathrm{Ar}$ plasma. The $\mathrm{Cl} 2 / \mathrm{Ar}$ gas flow was fixed at 15:5 sccm. The experimental condition was fixed at an (radio-frequency power?) of 600 $\mathrm{W}$, bias power of $200 \mathrm{~W}$ and process pressure of $2 \mathrm{~Pa}$.

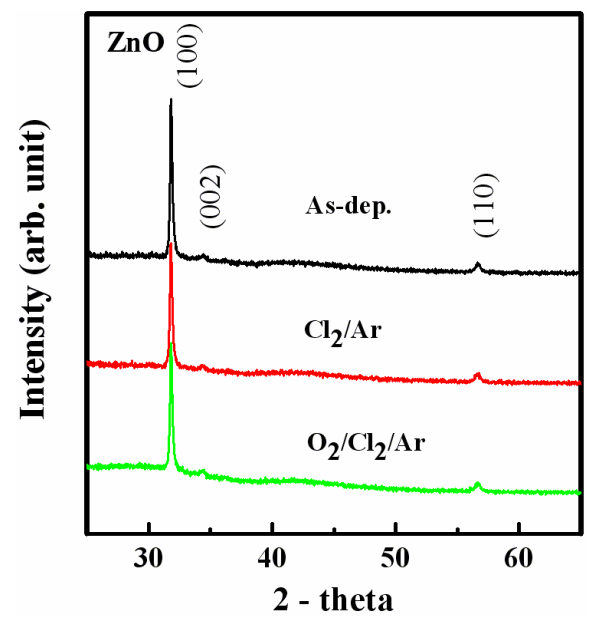

Fig. 3. Zinc oxide $(\mathrm{ZnO})$ diffraction patterns of samples after dry etching using $\mathrm{Cl} 2 / \mathrm{Ar}=15: 5 \mathrm{sccm}$ and $\mathrm{O} 2 / \mathrm{Cl} 2 / \mathrm{Ar}=4: 15: 5 \mathrm{sccm}$ plasma chemistries. Condition: radio-frequency power $=600 \mathrm{~W}$, bias power $=$ $200 \mathrm{~W}$, and process pressure $=2 \mathrm{~Pa}$.

volatile byproduct was $\mathrm{Zn}-\mathrm{Cl}$ compound which has a melting point of $290^{\circ} \mathrm{C}$. Also, the ion bombardment of the Ar ions supported the chemical reaction of $\mathrm{Cl}_{2}$ by breaking the zinc-oxide bonds. However, the results of the etch rate experiments indicate that the presence of Ar gas above a certain amount causes the etch rate to decrease.

We performed an $\mathrm{O}_{2}$ additive experiment under the previous $\mathrm{Cl}_{2} / \mathrm{Ar}$ experimental conditions, viz. a $\mathrm{Cl}_{2} / \mathrm{Ar}$ gas mixing ratio of 15:5 sccm, that showed the highest etch rate. The process pressure was $2 \mathrm{~Pa}$, the RF power was $600 \mathrm{~W}$, and the bias power was $200 \mathrm{~W}$. Figure 2 shows the etch rate of $\mathrm{ZnO}$ over quartz as a function of the $\mathrm{O}_{2}$ content in the $\mathrm{Cl}_{2} / \mathrm{Ar}$ plasma. The etch rate of the $\mathrm{ZnO}$ thin film at an $\mathrm{O}_{2}$ flow rate of $4 \mathrm{sccm}$ was $37.8 \mathrm{~nm} / \mathrm{min}$. As the $\mathrm{O}_{2}$ content increased up to $10 \mathrm{sccm}$, the etch rate of the $\mathrm{ZnO}$ thin film was increased to $19.9 \mathrm{~nm} / \mathrm{min}$. As the $\mathrm{O}_{2}$ content was increased in the $\mathrm{Cl}_{2} / \mathrm{Ar}$ plasma, the etch rate of the $\mathrm{ZnO}$ thin films decreased. Figure 3 shows the XRD $2 \theta$ patterns of the $\mathrm{ZnO}$ film etched using a $\mathrm{Cl}_{2} / \mathrm{Ar}$ sccm gas mixing ratio of 15:5 and an $\mathrm{O}_{2} / \mathrm{Cl}_{2} / \mathrm{Ar}$ gas mixing ratio of 4:15:5 $\mathrm{sccm}$ and of the as-deposited 


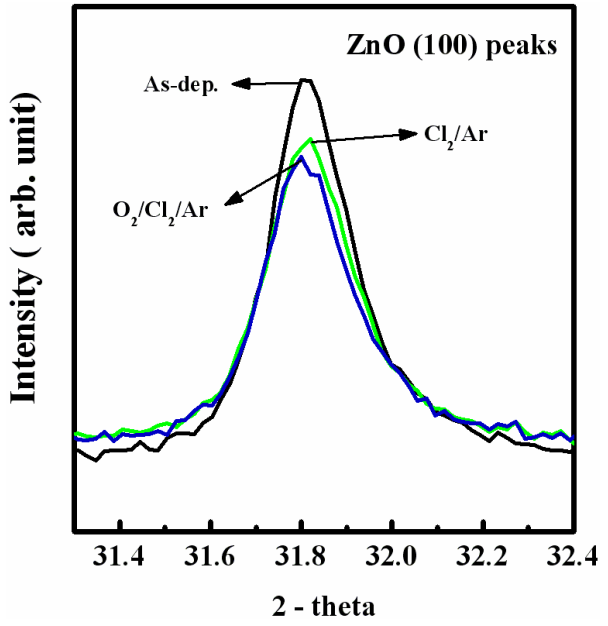

Fig. 4. Zinc oxide ( $\mathrm{ZnO})$ diffractograms of (100) peak in as-deposited film and films etched using $\mathrm{Cl} 2 / \mathrm{Ar}=15: 5 \mathrm{sccm}$ and $\mathrm{O} 2 / \mathrm{Cl} 2 / \mathrm{Ar}=4: 15: 5$ sccm plasma chemistries. Condition: radio-frequency power $=600 \mathrm{~W}$, bias power $=200 \mathrm{~W}$, and process pressure $=2 \mathrm{~Pa}$.

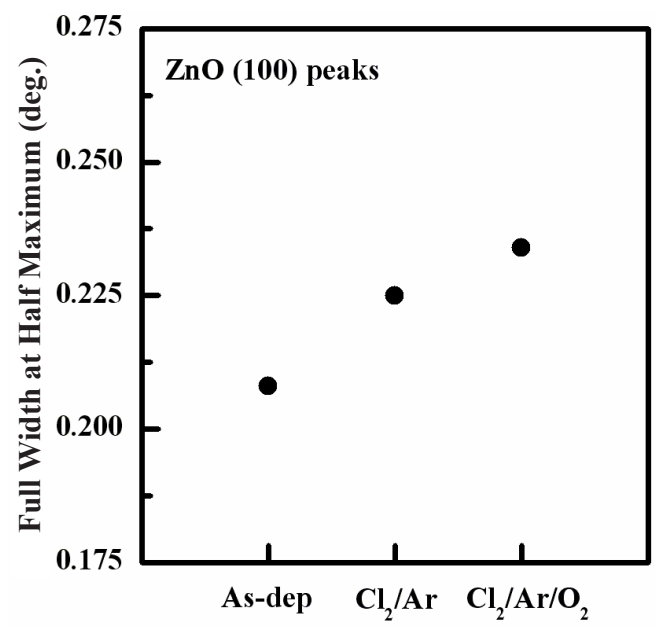

Fig. 5. Full width at half maximum values of X-ray diffraction diffraction patterns for as-deposited film and films etched using, $\mathrm{Cl} 2 / \mathrm{Ar}=$ 15:5 sccm and $\mathrm{O} 2 / \mathrm{Cl} 2 / \mathrm{Ar}=4: 15: 5 \mathrm{sccm}$ plasma chemistries. Condition: radio-frequency power $=600 \mathrm{~W}$, bias power $=200 \mathrm{~W}$, and process pressure $=2 \mathrm{~Pa}$.

sample. The experimental conditions included an RF power of $600 \mathrm{~W}$, bias power of $200 \mathrm{~W}$ and process pressure of $2 \mathrm{~Pa}$, The XRD pattern of the $\mathrm{ZnO}$ thin films was used to investigate the change in the crystal structure during plasma etching with $\mathrm{Cl}_{2}$ based chemistry. As shown in Fig. 3, a strongly oriented (100) peak and weak (002) and (110) peaks were detected in the XRD patterns of all of the samples [9-11]. We assume that the ALD method leads to the formation of a mainly one directional crystal structure. The XRD pattern of the films etched in the $\mathrm{Cl}_{2} / \mathrm{Ar}$ plasma was similar to that of the as-deposited sample. However, the fluctuation of the intensity of each peak means that the metal chloride compounds, ZnxCly, volatilized during the etching of the $\mathrm{ZnO}$ thin films. In this work, we assume that the chemical reaction of the $\mathrm{Cl}$ radicals and ion bombardment of argon gas are responsible for the changes in the properties of the $\mathrm{ZnO}$ thin film, including its crystallinity, and that the deposition method employed (ALD) inhibits the creation of a poly or amorphous structure.

Figure 4 shows the intensity of the (100) peaks in each gas (a)

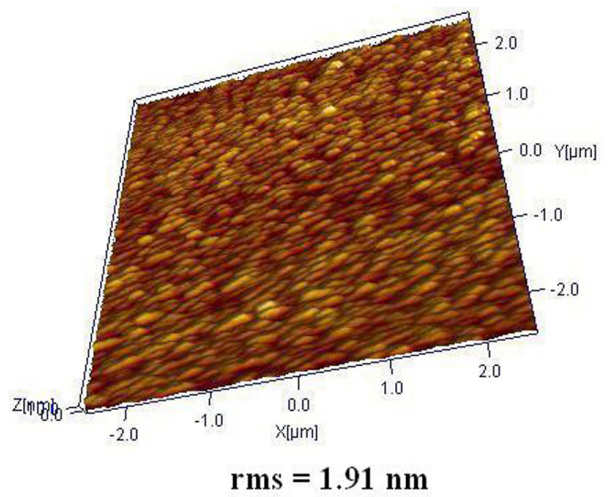

(b)

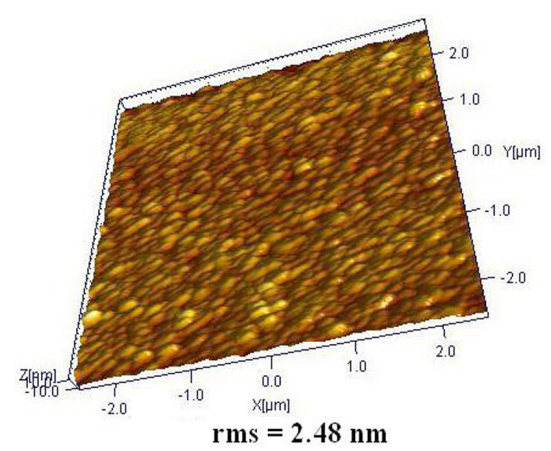

(c)

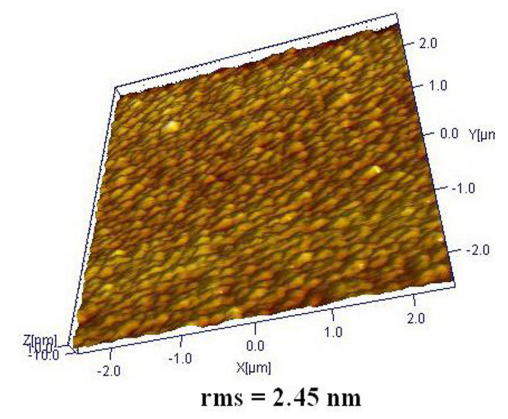

Fig. 6. Atomic force microscopy images for zinc oxide thin films (a) as-deposited (b) etched in $\mathrm{Cl} 2 / \mathrm{Ar}=15: 5$ plasma and (c) etched in $\mathrm{O} 2 /$ $\mathrm{Cl} 2 / \mathrm{Ar}=4: 15: 5$ plasma. Condition: radio-frequency power $=600 \mathrm{~W}$, bias power $=200 \mathrm{~W}$, and process pressure $=2 \mathrm{~Pa}$.

Table 1. Variation of FWHM and grain size of the XRD (002) peaks with the plasma

\begin{tabular}{lll}
\hline Sample & FWHM (degree) & Grain size $(\mathrm{nm})$ \\
\hline \hline As-deposited & 0.208 & 0.69 \\
$\mathrm{Cl}_{2} / \mathrm{Ar}$ & 0.225 & 0.64 \\
$\mathrm{O}_{2} / \mathrm{Cl}_{2} / \mathrm{Ar}$ & 0.234 & 0.61 \\
\hline
\end{tabular}

FWHM: full width at half maximum, XRD: X-ray diffraction.

mixture at a fixed RF power of $600 \mathrm{~W}$, bias power of $200 \mathrm{~W}$, and process pressure of $2 \mathrm{~Pa}$. The results of the XRD analysis showed that the peak intensities of the etched $\mathrm{ZnO}$ thin films differed from those of the as-deposited sample. The (100) peak of the as-deposited film shows the high intensity, while those of the samples decreased with the increased $\mathrm{O}_{2}$ content. The (100) peak intensity was decreased after etching in the $\mathrm{Cl}_{2} / \mathrm{Ar}$ plasma. Also, the intensity of the (100) peak of the film etched in the $\mathrm{O}_{2} /$ $\mathrm{Cl}_{2} / \mathrm{Ar}$ plasma was lower than that of the as-deposited sample. Moreover, the XRD peak of the film etched in the $\mathrm{Cl}_{2} / \mathrm{Ar}$ plasma was shifted to a higher diffraction angle. This indicates that the 


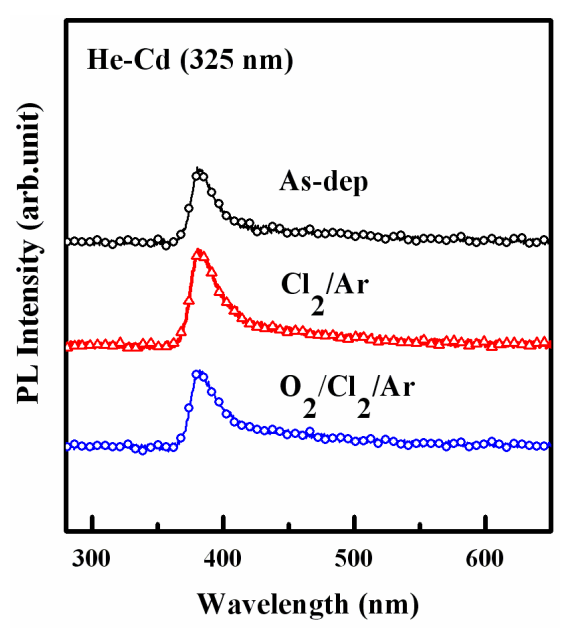

Fig. 7. Photoluminescence (PL) spectra at room temperature of asdeposited zinc oxide thin films and those etched in $\mathrm{Cl} 2 / \mathrm{Ar}=15: 5$ sccm and $\mathrm{O} 2 / \mathrm{Cl} 2 / \mathrm{Ar}=4: 15: 5$ sccm plasma chemistries. Condition: radio-frequency power $=600 \mathrm{~W}$, bias power $=200 \mathrm{~W}$, and process pressure $=2 \mathrm{~Pa}$.

etched sample in the $\mathrm{Cl}_{2}$ /Ar plasma experience more stress, whereas the etched sample in the $\mathrm{O}_{2} / \mathrm{Cl}_{2} / \mathrm{Ar}$ plasma shows less stress $[12,13]$. These observations allow us to assume that the use of the $\mathrm{Cl}_{2}$-based chemistry during the etching process highly modifies the $\mathrm{ZnO}$ thin film crystal structure. We suggest that the Ar ion bombardment induces stress in the $\mathrm{ZnO}$ thin films and decreases the intensities of the XRD peaks caused by the chemical reaction with $\mathrm{Cl}$ and $\mathrm{O}$ radicals, which changes the chemical purity of the $\mathrm{ZnO}$ thin film. Figure 5 shows the full width at half maximum (FWHM) value of the (100) peak of the film etched in the $\mathrm{Cl}_{2}$ / Ar gas mixture and the FHWM values and grain size calculated using Scherrer's equation for each plasma chemistry are shown in Table 1 . The XRD diffraction results indicate that the ion bombardment and chemical reaction change the crystalline structure of the $\mathrm{ZnO}$ thin film. In the $\mathrm{Cl}_{2} / \mathrm{Ar}$ plasma chemistry, the FWHM value was increased and the grain size was decreased, indicating that the crystallinity of the $\mathrm{ZnO}$ thin films was modified by the ion bombardment or chemical reaction. Also, the $\mathrm{O}_{2} / \mathrm{Cl}_{2} / \mathrm{Ar}$ sample has a higher FWHM value and lower grain size than the other films. In previous experiments, the shift of the FWHM value to a high value indicated that the crystalline structure was changed [9-11] and this change in the grain size influenced the physical properties of the thin films. According to the FHWM values and grain size, the modification of the physical properties of the $\mathrm{ZnO}$ thin films can be explained by the chemical reaction of the $\mathrm{Cl}$ radicals, which make it difficult for the films to keep their original crystalline structure. Also, the FWHM value of the $\mathrm{O}_{2} / \mathrm{Cl}_{2} / \mathrm{Ar}$ sample is very different from that of the as-deposited one, indicating that the $\mathrm{O}_{2}$ gas affects the crystal structure and crystallinity. As a result, it can be concluded that the small perturbations of the FWHM value $(\sim 0.1 \theta)$ correspond to the damage or modification of the crystallinity induced by the plasma etching, which was mainly caused by chemical reactions.

Figure 6 shows the three-dimensional (3D) AFM images of the $\mathrm{ZnO}$ thin films etched in the $\mathrm{Cl}_{2} / \mathrm{Ar}=15: 5 \mathrm{sccm}$ plasma and $\mathrm{O}_{2} /$ $\mathrm{Cl}_{2} / \mathrm{Ar}=4: 15: 5 \mathrm{sccm}$ plasmas. The experimental conditions were a fixed RF power of $600 \mathrm{~W}$, bias power of $200 \mathrm{~W}$, and process pressure of $2 \mathrm{~Pa}$. Figure 6(a) show that the rms roughness of the asdeposited sample was $1.91 \mathrm{~nm}$. As shown in Figs. 6(b) and (c), the $\mathrm{ZnO}$ thin film samples which were etched using the $\mathrm{Cl}_{2} / \mathrm{Ar}=$ 15:5 sccm and $\mathrm{O}_{2} / \mathrm{Cl}_{2} / \mathrm{Ar}=4: 15: 5 \mathrm{sccm}$ plasmas had rms roughnesses of $2.48 \mathrm{~nm}$ and $2.45 \mathrm{~nm}$, respectively. Thus, the etched samples generally had higher rms roughnesses than the as-deposited one. However, the $\mathrm{O}_{2} / \mathrm{Cl}_{2} / \mathrm{Ar}$ plasma sample had a lower rms roughness than the $\mathrm{Cl}_{2} / \mathrm{Ar}$ plasma sample.

We obtained the photoluminescence spectra of the $\mathrm{ZnO}$ thin films at room temperature. Figure 7 shows the PL spectra of the $\mathrm{ZnO}$ thin films in the as-deposited state and after etching using the $\mathrm{Cl}_{2} / \mathrm{Ar}=15: 5 \mathrm{sccm}$ and $\mathrm{O}_{2} / \mathrm{Cl}_{2} / \mathrm{Ar}=4: 15: 5 \mathrm{sccm}$ plasma chemistries. The experimental conditions were a fixed RF power of 600 $\mathrm{W}$, bias power of $200 \mathrm{~W}$, and process pressure of $2 \mathrm{~Pa}$. The films etched in the $\mathrm{Cl}_{2} / \mathrm{Ar}$ and $\mathrm{O}_{2} / \mathrm{Cl}_{2} / \mathrm{Ar}$ plasma chemistries showed similar PL spectra to those of the as-deposited sample. The PL spectra of the as-deposited $\mathrm{ZnO}$ thin films showed a strong band-edge luminescence at $380 \mathrm{~nm}(3.26 \mathrm{eV})$ and absence of any deep-level emission $(2.4 \sim 2.6 \mathrm{eV})$, while those of the samples etched in both the $\mathrm{Cl}_{2} / \mathrm{Ar}$ and $\mathrm{O}_{2} / \mathrm{Cl}_{2} / \mathrm{Ar}$ chemistries also showed the same band-edge luminescence with increased intensities and no deep-level emission. In etching experiment, the bandedge luminescence of the $\mathrm{ZnO}$ thin film, which was deposited on a quartz substrate using the atomic layer deposition method, was improved such that it has a strong band-edge luminescence and no deep-level emission. According to previous studies, the plasma induced damage and native defects, such as $O$ vacancies and $\mathrm{Zn}$ interstitials, contribute to the creation of a deeplevel emission $[4,14,15]$. However, no deep level emission was found in the PL spectra of the $\mathrm{ZnO}$ thin films prepared in this work, which means that there were no native defects in the $\mathrm{ZnO}$ samples, as compared to those of the $\mathrm{ZnO}$ thin films deposited by sputtering which showed strong deep level emissions $[15,16]$. The etched ZnO sample prepared using ALD showed better band-edge luminescence and no deep level emission, indicating that this method produces films having better quality than those prepared by the sputtering method.

\section{SUMMARY AND CONCLUSIONS}

We investigated the plasma induced damage and modification of $\mathrm{ZnO}$ thin films etched using a $\mathrm{Cl}_{2} / \mathrm{Ar}$ plasma alone and one to which $\mathrm{O}_{2}$ gas was added for the dry etching process. The plasma gas chemistry influenced the physical and optical properties of the $\mathrm{ZnO}$ thin film. When the experimental condition was an RF power of $600 \mathrm{~W}$, bias power of $200 \mathrm{~W}$, gas mixture of $\mathrm{Cl}_{2} / \mathrm{Ar}=15: 5$ sccm, and process pressure of $2 \mathrm{~Pa}$, the maximum etch rate of $40.3 \mathrm{~nm} / \mathrm{min}$ was obtained for the $\mathrm{ZnO}$ thin films. Also, the etch rate of the $\mathrm{ZnO}$ thin film at an $\mathrm{O}_{2}$ flow of $4 \mathrm{sccm}$ was $37.8 \mathrm{~nm} /$ min. As the $\mathrm{O}_{2}$ content increased up to $10 \mathrm{sccm}$, the etch rate of the $\mathrm{ZnO}$ thin film was decreased. In the XRD analysis, a strongly oriented (100) ZnO peak and weak (002) and (110) ZnO peaks were detected. The high FWHM values obtained in the XRD analysis of the $\mathrm{ZnO}$ thin films indicates that the plasma chemistry modifies or damages their physical properties. According to the 3D AFM image, the surface roughness of the as-deposited sample was $1.91 \mathrm{~nm}$. However, the surface roughnesses of the etched samples, viz. $2.48 \mathrm{~nm}$ in the $\mathrm{Cl}_{2} / \mathrm{Ar}$ plasma and $2.45 \mathrm{~nm}$ in the $\mathrm{O}_{2} / \mathrm{Cl}_{2} / \mathrm{Ar}$ plasma, were the higher than that of the asdeposited sample. In the conventional dry etching mechanism, the ion flux and ion bombardment of inert gas ion promote the physical etching mechanism and chemical reactions by breaking the bonds of the chemical compounds. From the XRD and AFM analysis, it was found that the film etched using the $\mathrm{O}_{2} / \mathrm{Cl}_{2}$ / Ar plasma chemistry showed a low rms roughness, high FWHM value and large grain size. The oxygen ions cause the low rms roughness and have an influence on the chemical reactions during etching, leading to the large FWHM value and grain size. Therefore, we suggest that the plasma gas chemistry during the etching process contributed to the modification of the crystal 
structure and grain size, however the resultant plasma induced damage was insufficient to reduce the optical properties. For this reason, further studies using chemical analysis are required to clearly explain the relation between the PL intensity and plasma chemistry in the case of $\mathrm{ZnO}$ thin films.

\section{REFERENCES}

[1] D. C. Look, Mater. Sci. Eng. B 80, 383 (2001) [DOI: 10.1016/ s0921-5107(00)00604-8].

[2] Y. W. Heo, Y. W. Kwon, Y. Li, S. J. Pearton, and D. P. Norton, Appl. Phys. Lett. 84, 3474 (2004) [DOI: 10.1063/1.1737795].

[3] D. C. Look, D. C. Reynolds, J. R. Sizelove, R. L. Jones, C. W. Litton, G. Cantwell, and W. C. Harsch, Solid State Commun. 105, 399 (1998) [DOI: 10.1016/s0038-1098(97)10145-4].

[4] L. Schmidt-Mende and J. L. MacManus-Driscoll. Mater. Today 10, 40 (2007).

[5] W. Lim, L. Voss, R. Khanna, B. P. Gila, D. P. Norton, S. J. Pearton, and F. Ren, Appl. Surf. Sci. 253, 889 (2006) [DOI: 10.1016/ j.apsusc.2006.01.037].

[6] S. W. Na, M. H. Shin, Y. M. Chung, J. G. Han, S. H. Jeung, J. H. Boo, and N. E. Lee, Microelectron. Eng. 83, 328 (2006) [DOI: 10.1016/j.mee.2005.09.007].

[7] J. C. Woo, G. H. Kim, J. G. Kim, and C. I. Kim, Surf. Coat. Technol. 202, 5705 (2008) [DOI: 10.1016/j.surfcoat.2008.06.077].

[8] J. C. Woo, D. S. Um, and C. I. Kim, Thin Solid Films 518, 2905 (2010) [DOI: 10.1016/j.tsf.2009.10.144].

[9] J. L. van Heerden and R. Swanepoel, Thin Solid Films 299, 72 (1997) [DOI: 10.1016/s0040-6090(96)09281-4].

[10] G. Srinivasan and J. Kumar, Cryst. Res. Technol. 41, 893 (2006) [DOI: 10.1002/crat.200510690].

[11] S. A. M. Lima, F. A. Sigoli, M. Jafelicci Jr, and M. R. Davolos, Int. J. Inorg. Mater. 3, 749 (2001) [DOI: 10.1016/s1466-6049(01)00055$1]$.

[12] S. J. An, W. I. Park, G. C. Yi, Y. J. Kim, H. B. Kang, and M. Kim, Appl. Phys. Lett. 84, 3612 (2004) [DOI: 10.1063/1.1738180].

[13] A. Chatterjee, C. H. Shen, A. Ganguly, L. C. Chen, C. W. Hsu, J. Y. Hwang, and K. H. Chen, Chem. Phys. Lett. 391, 278 (2004) [DOI: 10.1016/j.cplett.2004.05.021].

[14] J. S. Park, H. J. Park, Y. B. Hahn, G. C. Yi, and A. Yoshikawa, J. Vac. Sci. Technol. B 21, 800 (2003) [DOI: 10.1116/1.1563252].

[15] J. M. Lim and C. M. Lee, Thin Solid Films 515, 3335 (2007) [DOI: 10.1016/j.tsf.2006.09.007].

[16] K. K. Kim, J. H. Song, H. J. Jung, W. K. Choi, S. J. Park, and J. H. Song, J. Appl. Phys. 87, 3573 (2000) [DOI: 10.1063/1.372383]. 